\title{
A la espera de una semiótica de los tesoros
}

\author{
Umberto ECO \\ Traducción de Eva Aladro Vico
}

Mientras esperamos a que Omar Calabrese quiera construir una semiótica de los tesoros, me limitaré a sugerir a los amantes del arte, que dejen por un instante las capillas sixtinas y las giocondas y vayan en busca de los tesoros. Es una experiencia apasionante: merece la pena hacer ese viaje, organizándolo bien, y siguiendo un itinerario que lleve a tocar los tesoros más interesantes, hallándolos hasta en las abadías menos importantes. Puede que ya no valga la pena trasladarse a Saint Denis, a las puertas de París, donde en el siglo XII el gran Suger, coleccionista refinadísimo, devoto de las gemas, de las perlas, de los marfiles, de los candelabros de oro, de los retablos de altar ornamentados, hizo de la acumulación de objetos preciosos una especie de religión y una teoría filosófico-mística. Desgraciadamente, relicarios, jarrones sagrados, ropajes vestidos por el rey en su ceremonia de consagración, la corona fúnebre de Luis XVIII y de María Antonieta, el retablo de la Adoración de los Pastores donado por el Rey Sol, se han dispersado todos, pero algunas de las piezas más finas todavía pueden rencontrarse en el Louvre.

Sin embargo, no se puede dejar de visitar la catedral de San Vito, en Praga, donde podemos hallar los cráneos de San Adalberto y San Wenceslao, la espada de San Esteban, un fragmento de la Cruz, el mantel de la Última Cena, un diente de Santa Margarita, un fragmento de la tibia de San Vital, una costilla de Santa Sofia, el mentón de San Eobano, el cayado de Moisés, el vestido de la Virgen. El anillo de compromiso de San José estaba en el catálogo del fabuloso tesoro del duque de Berry, hoy disperso, pero que debiera encontrarse en Nôtre Dame de París, mientras que en el tesoro imperial de Viena se puede admirar un pedazo del pesebre de Belén, la bolsa de San Esteban, la lanza que se clavó a Jesús en el costado con un clavo de la Cruz, la espada de Carlo Magno, un diente de San Juan Bautista, un hueso del brazo de Santa Ana, las cadenas de los apóstoles, un pedazo del vestido de Juan Evangelista, y otro fragmento del mantel de la Santa Cena.

Cuando prestamos atención a los tesoros, encontramos algunos muy cercanos que son ignorados. Creo que por ejemplo poquísimos milaneses han visitado el tesoro del Duomo. Si se lo consigue encontrar abierto, se puede admirar allí una 
cubierta del evangelio de Ariberto (siglo XI) con deliciosas placas de esmalte doisonné (alveolado), filigrana de oro, y engastada con piedras preciosas. La búsqueda de piedras preciosas y de sus diversas cualidades es una de las diversiones preferidas de los apasionados de los tesoros, porque se trata de reconocer no solo al diamante o al rubí o la esmeralda, sino también las piedras que siempre hallamos citadas en los textos sagrados, como el ópalo, el crisopacio, el berilo, el ágata, el jaspe, la sardónica. Si somos expertos, deberemos saber reconocer las piedras buenas, frente a las falsas; también en el tesoro de la catedral milanesa hay una gran estatua de plata de San Carlos, de época barroca, que, aunque a los que la encargaron o la donaron, la plata parecía entonces poca cosa todavía, muestra un pectoral con cruz que es un fulgurar de piedras preciosas. Y algunas de ellas, dice el catálogo, son auténticas, pero otras no lo son, son cristales coloreados. Pero dejando de lado algún remilgo material, se debe disfrutar sobre todo de lo que los constructores de objetos así querían obtener, como es un efecto global de deslumbre y de riqueza. Incluso porque la mayor parte de los materiales preciosos de los tesoros son auténticos, y si comparamos un expositor lateral de un tesoro de este tamaño, con el escaparate del mejor joyero de Paris, este no vale ni para un puesto en el mercado de pulgas.

Sugeriría después echar una mirada a la laringe de San Carlos Borromeo, y permanecer más atento ante la Paz de Pío IV, que es una pequeña edificación con dos columnas en lapislázuli y oro que enmarcan la ubicación del sepulcro de oro. Sobre él hay una cruz áurea con trece diamantes en un tondo de ónice veteado, y el pequeño frontispicio está cuajado de oro, ágatas, lapislázuli y rubíes. Pero remontándonos en el tiempo, hallamos una cajita del período ambrosiano, para reliquias de los apóstoles, de plata en relieve, con magníficos bajorrelieves - aunque en materia de bajorrelieves sea más fascinante un místico retablillo de marfil, llamado Díptico de las cinco partes, proveniente de la Ravenna del siglo V, con escenas de la vida de Cristo, y en el centro un Cordero Místico en alveolos de plata dorada con pasta de vidrio, única imagen de color suave sobre un fondo de marfil envejecido.

Estos son ejemplos de una tradición histórica que desgraciadamente nos hemos habituado a llamar artes menores. Obviamente se trata de arte sin adjetivo, y si hay algo en ellos "menor" (que artísticamente valga menos) es precisamente el Duomo mismo. Si llegara el diluvio universal y me dieran a escoger entre salvar el Duomo o salvar el Díptico de las Cinco Partes, escogería sin dudas este último, y no porque sea más fácilmente acomodable en el Arca.

Sin embargo, también si consideramos la capilla adyacente llamada la Custodia de San Carlos, con el cuerpo del santo y un contenedor en cristal y plata que me pareció siempre más milagroso que su contenido, el tesoro del Duomo no muestra todo lo que podría mostrar. Consultando el Inventario de las vestiduras y ornamentos sagrados del Duomo de Milán, nos damos cuenta de que el Tesoro propiamente dicho es tan solo una mínima parte del conjunto, disperso en las varias sacristías, que reúne vestiduras espléndidas, jarrones, marfiles, oros y reliquias gustosísimas, como algunas espinas de la corona de Jesús, un pedazo de la Cruz, y restos variados de santa Ágnes, santa Ágata, santa Caterina, santa Práxedes y de los santos Simpliciano, Cayo y Geruncio. 
Cuando se visita un tesoro no es necesario acercarse a las reliquias con ánimo científico, pues si así fuera nos arriesgaríamos a perder la fe, pues ya sabemos que las crónicas antiguas relatan que en el siglo XII en una catedral alemana se conservaba el cráneo de San Juan Bautista a la edad de doce años. Pero en una ocasión, en el monasterio del Monte Atos, hablando con el monje bibliotecario, supe que había sido alumno de Roland Barthes en París y que había vivido el mayo del 68 - por tanto, sabiéndolo hombre de cultura, le pregunté si creía en la autenticidad de las reliquias que devotamente besaba cada mañana al amanecer, durante una interminable y soberbia liturgia religiosa. Él me sonrió con dulzura, con una cierta complicidad maliciosa, y contestándome, me dijo que el problema no estaba en la autenticidad sino en la fe, y que él, al besar las reliquias, advertía en ellas el perfume místico. En suma, no es la reliquia la que hace a la fe, sino la fe la que hace la reliquia.

Pero ni el mayor descreído puede sustraerse a la fascinación de esos dos portentos. Primero el objeto mismo, esos cartílagos anónimos y amarillentos, místicamente repugnantes, patéticos y misteriosos; esos jirones de ropa, de vete a saber qué época, descoloridos, desteñidos, deshilachados, a veces enrollados dentro de una redoma como un misterioso manuscrito en una botella, de materia a menudo desmenuzada, que se confunden con la estofa, y el metal o el hueso que yacen entre ellos. Y en un segundo lugar los contenedores, a menudo de una riqueza increíble, a veces construidos por un bricoleur devoto con piezas de otros relicarios, en forma de torre, de pequeña catedral con pináculos y cúpulas, hasta llegar a ciertos relicarios barrocos (los más bellos están en Viena) que son una selva de diminutas esculturas, que asemejan a relojes, carillones, cajas mágicas. Algunos recuerdan, para los amantes del arte contemporáneo, a las cajas surrealistas de Joseph Cornell y las tecas llenas de objetos serializados de Arman —relicarios laicos, pero que exhiben el mismo gusto por los materiales consumidos y polvorientos, por la acumulación forzada, e imponen una visión analítica, diminuta, que se rechaza al primer golpe de vista.

Amar los tesoros significa también comprender cuál era el gusto tanto de los antiguos mecenazgos medievales como de los coleccionistas renacentistas y barrocos, y también de las cámaras maravillosas (wünderkammern) de los príncipes alemanes: no existía una distinción nítida entre el objeto devoto, el hallazgo raro y la obra de arte. Un relieve en marfil era precioso bien por su factura (hoy diríamos que por su arte), tanto como por el valor de la materia. Y era considerado en un mismo título precioso, gozoso, maravilloso, extraño, y por eso el duque de Berry alineaba juntos los cálices y los vasos de gran valor artístico con un elefante disecado, un basilisco, un huevo que un abad había encontrado dentro de otro huevo, maná del desierto, una nuez de coco y un cuerno de unicornio. ¿Se ha perdido todo? No, porque un cuerno de unicornio puede verse también en el tesoro de Viena, y nos proporciona la certidumbre de que los unicornios existieron, aunque el catálogo nos informe, con despiadado positivismo, de que se trata de un cuerno de narval.

Pero en este punto, el visitante iniciado en el espíritu del buen amante de tesoros, mirará con el mismo interés el cuerno, una copa de ágata del siglo IV, que la tradición quiere que sea el cáliz del Grial, que la corona, el globo y el cetro imperial (esplendor de la orfebrería medieval) y, como el Tesoro de Viena no conoce límites 
en el tiempo, la cama de columnillas imperiales en la que durmió el infortunado hijo de Napoleón, el Rey de Roma, llamado l'Aiglon (el Aguilucho, que en este punto se hace tan legendario como los unicornios o el Grial).

Y se debe ser capaz de olvidar lo que se ha leído en la historia del arte, de perder el sentido de las diferencias entre curiosidades y obras maestras, para disfrutar sobre todo del montón de maravillas, la hilera de prodigios, la epifanía de lo increíble. Y soñar el cráneo de San Juan a la edad de doce años, saboreando las venas rosadas, el color ceniza de fondo, el arabesco de las articulaciones deshechas y corrompidas, y la caja que lo contiene, con sus esmaltes azul cian, como el altar de Verdún con su cojincillo interno de raso amarillento, cubierto de roselinas ajadas en la caja de cristal, sin aire desde hace dos mil años, todo inmovilizado al vacío, antes de que el Bautista creciese y perdiese bajo la espada del verdugo el otro cráneo, más maduro, pero de menor valor místico y comercial, porque si una presunta testa se conserva en la Iglesia de San Silvestre en Capite en Roma, una tradición precedente la situaba en la catedral de Amiens, además de que la cabeza custodiada en Roma debía carecer de mandíbula, porque esta se reivindicaba en la iglesia de San Lorenzo de Viterbo.

Por lo demás, basta coger el mapa y fijar los itinerarios factibles. Por ejemplo la Vera Cruz, descubierta en Jerusalén por Santa Elena, madre de Constantino, fue sustraída por los persas en el siglo VII, y después recuperada por el emperador bizantino Heráclito. En 1187 fue llevada por los Cruzados al campo de batalla de Hattin, para asegurar su victoria contra Saladino; sin embargo como es sabido la batalla se perdió y con ella el rastro de la Cruz para siempre. Pero en los siglos precedentes se habían extraído numerosos fragmentos que fueron conservados todavía en muchas iglesias.

Los tres clavos (dos de las manos y uno de los pies clavados juntos) que se hallaron todavía unidos a la cruz, fueron llevados por Elena a su hijo Constantino: según la leyenda uno de ellos fue montado en el casco de batalla del mismo, con otro sin embargo se creó el bocado de su caballo. El tercer clavo, según la tradición, se conserva en la iglesia de Santa Cruz de Jerusalén de Roma. El Sagrado Bocado en cambio se encuentra en el Duomo de Milán, donde dos veces al año se muestra a los fieles. Del clavo montado en el casco se han perdido las trazas; según una tradición se halla hoy en la Corona Férrea, conservada en la Catedral de Monza.

La corona de espinas se conservó por mucho tiempo en Constantinopla, después fue cedida al rey Luis IX de Francia, que la colocó en la Sainte Chapelle, hecha construir ex profeso en París. En origen la corona tenía decenas de espinas, pero con el paso de los siglos fueron donándose a iglesias, santuarios y a personajes importantes, y hoy le quedan solo las ramas entrelazadas en forma de casco.

La columna de la flagelación está en Roma en Santa Práxedes, la Sagrada Lanza, que perteneció a Carlomagno y a sus sucesores, hoy se encuentra en Viena, el Prepucio de Jesús se conservaba y exponía el primer día del año en Calcata, pueblecito viterbés, hasta 1970, cuando el párroco comunicó su hurto. Pero de reliquia análoga han reivindicado posesión Roma, Santiago de Compostela, Chartres misma, Besançon, Metz, Hildesheim, Charroux, Conques, Langres, Anversa, Fécamp, Puy-en-Velay, Auvergne. 
La sangre de Jesús proveniente de la herida del costado, según la tradición, fue recogida por el soldado Longino, quien asestó la lanzada: él la habría llevado a Mantua; la ampolla contenedora de la presunta sangre se custodia en la catedral de la ciudad. Otra sangre atribuida a Jesús se conserva en una caja cilíndrica visible en la Basílica de la Santa Sangre (Heilig-Bloedbasiliek) en Brujas (Bélgica).

La Santa Cuna está en Santa María la Mayor (Roma), la Sábana Santa está como es sabido en Turín, la toalla de lino usada por Jesús para lavar los pies de los apóstoles está en la iglesia romana de San Juan en Laterano, pero también en Alemania, en Acqs. Esta última toalla incluso se dice que lleva la huella de los pies de Judas.

Los pañales del niño Jesús están en Aquisgrán, los restos del pesebre en el que se le dio aposento están en Santa María la Mayor de Roma, la habitación de María, donde recibió la Anunciación, fue transportada en vuelo de Nazaret a Loreto por algunos ángeles, en muchas iglesias se conservan presuntos cabellos de María (por ejemplo hay un cabello en Mesina), su leche, la sagrada cinta (o cinturón de la Virgen) está en Prato, el anillo nupcial de San José en Perugia, en la Catedral, los anillos de compromiso de José y María en Notre Dâme, París, el cinturón de José (llevado en 1254 desde Joinville) está en la Iglesia des Feuillants en París, su bastón en los Camaldolesios de Florencia. Fragmentos de ese bastón se hallan también en: Santa Cecilia en Roma, Santa Anastasia en Roma, Santo Domingo en Bolonia, San José del Mercado. Fragmentos de la tumba de San José se encuentran en Santa María al Pórtico y en Santa María ai Campitelli de Roma.

Fragmentos del santo velo de la Virgen y de la chaqueta de San José se hallan en Santa María de Licodia, conservados en un artístico relicario de plata, obra del siglo XVIII. Este relicario era sacado en procesión hasta los años 70 del siglo XX, el último sábado del mes de agosto, con ocasión de la fiesta patronal.

El cuerpo de San Pedro fue sepultado en Roma en un lugar cercano al de su martirio, junto al Circo de Nerón; sobre el lugar se construyó la homónima basílica constantiniana y después la actual Basílica de San Pedro. En 1964, tras una campaña de excavaciones arqueológicas, se anunció el hallazgo de los huesos del apóstol, que hoy están ubicados bajo el altar.

El cuerpo de Santiago el Mayor, según la leyenda, fue transportado por la corriente del mar hasta la costa atlántica de España y sepultado en un lugar llamado campus stellae. En tal localidad emerge hoy el santuario de Santiago de Compostela, desde la Edad Media uno de los principales destinos de peregrinación junto a Roma y Jerusalén.

El cuerpo del apóstol Tomás, custodiado en la Catedral de Ortona (Chieti), fue llevado en el 1258 desde Kíos, isla del Mar Egeo, donde había sido protegido por los cristianos tras la caída de Edesa en 1146. A Edesa había llegado desde Madrás (India), tras el martirio del 72 , en torno al año 230 y por orden del emperador Alejandro Severo.

Uno de los treinta denarios por los que Judas Iscariote traicinó a Cristo, en la sacristía de la Colegiata de Visso. Un cuerpo de San Bartolomé apóstol está en Roma (trasladado a la Isla Tiberina por Pio IV), otro en San Bartolomé en Benevento. En cualquier caso a ambos cuerpos debería faltar la coronilla, porque una se conserva en la Catedral de Frankfurt y la otra en el monasterio de Lune (Luneburg). Pero no 
sé de cuál cuerpo pueda provenir la tercera coronilla, que se halla en la Cartuja de Colonia. Siempre de San Bartolomé, un brazo está en la Catedral de Canterbury, pero Pisa alardeaba de poseer parte de la piel del santo.

El cuerpo de un Lucas Evangelista se custodia cerca de la iglesia de Santa Justina en Padua, y el de San Marcos, custodiado primero en Antioquía, fue después llevado a Venecia.

En Milán se conservaban antiguamente los presuntos restos de los Reyes Magos. En el siglo XII el emperador Federico Barbarroja los tomó como botín de guerra y los llevó a Colonia, donde ahora se hallan. Algunos restos fueron devueltos a Milán en los años 50 y depositados en San Eustorgio.

Los restos de San Nicolás de Bari, o Santa Claus, se custodiaban en Myra, en Asia Menor. En 1087 fueron robados por algunos marineros de Bari y llevados a su ciudad.

El cuerpo de San Ambrosio, patrón de Milán, está sepultado en la cripta de la basílica a él dedicada, junto con los cuerpos de los santos Gervasio y Protasio.

En la Basílica de San Antonio de Padua se conservan la lengua y los dedos del santo, la mano de San Esteban de Hungría se conserva en la Basílica de Budapest, las ampollas con la sangre de San Jenaro están obviamente en Nápoles, parte del cuerpo de santa Judith está en la catedral de Nevers mientras que un fragmento óseo se conserva en un precioso relicario de cristal de roca colocado en la cripta de las tumbas de los Médicis en San Lorenzo, en Florencia.

En Misterbianco se expone, cada 17 de enero, el brazo de San Antonio Abad, el de San Benedicto de Norcia fue donado al Monasterio de Leno en el siglo VIII a petición del rey Desiderio.

El cuerpo de Santa Ágata en Catania se subdivide en varios relicarios, y los orfebres de Limoges construyeron relicarios para los miembros, uno para cada fémur, uno para cada brazo, uno para cada pierna. En 1628 se realizó el de la mama. Pero cúbito y radio de un brazo están en Palermo, en la Capilla Regia. Un hueso del brazo de Santa Ágata en Mesina, en el Monasterio del Smo. Salvador, otro en Alí, un dedo de Santa Ágata está en Santa Ágata dei Goti (Benevento), el cuerpo de San Pedro de Verona está en la Capilla Portinari en San Eustorgio en Milán (el 29 de abril se acostumbra darse un coscorrón en la cabeza para preservarla del dolor de cabeza).

Los restos de San Gregorio Nacianceno están en San Pedro, en Roma, pero una parte fue donada por Juan Pablo II al patriarca de Constantinopla en 2004. Reliquias de San Lúcido se encuentran en Aquarara: robadas varias veces, finalmente la cabeza fue recuperada por las fuerzas de orden público en una casa privada en 1999. Reliquias de San Pantaleón se encuentran en la homónima iglesia de Lanciano (la espada que truncó la cabeza del santo, la rueda dentada con la que se martirizó el cuerpo, la espatulilla con la que se quemaron las heridas, un tronco de olivo que floreció en contacto con el cuerpo).

Una costilla de Santa Caterina está en Astenet en Bélgica, un pie en la Iglesia de los Santos Juan y Pablo en Venecia. Un dedo y la cabeza (separada del cuerpo en 1381 por voluntad del Papa Urbano VI) están en la Basílica de Santo Domingo en Siena.

Un pedazo de la lengua de San Biagio está en Carotino, un brazo en la Catedral de Ruvo en Puglia, el cráneo en Dubrovnik. Encontramos un diente de Santa 
Apolonia en la Catedral de Porto, el cuerpo de San Ciríaco en el Duomo de Ancona, el corazón de San Alfo en Lentini, el cuerpo de San Rocco en Venecia, en el Altar Mayor de la Iglesia de la Archiconfraternidad Escuela Grande la apófisis que forma parte de la escápula y otro fragmento óseo en Sicilia, parte de un hueso del brazo en la homónima iglesia de Voghera, otra porción de un hueso del brazo en la homónima iglesia de Roma, una tibia y otras partes de la masa corporis y el que se presume fue su bastón en su santuario de Montpellier, una falange en la parroquial de Cisterna de Latina, una parte de talón en la catedral de Frigento, algunos fragmentos de huesos en la Basílica Mauriziana y en la iglesia de la Confraternidad de San Rocco en Turín.

En Constantinopla se veneraban reliquias después dispersas tras la cuarta cruzada, como el manto de la Virgen (el maphorion), las sandalias de Cristo, la chaqueta de San Juan Bautista, una ampolla con la sangre de Cristo, que se utilizaba para firmar ciertos documentos solemnes, el brocal del pozo delante del cual tuvo lugar el episodio evangélico de Cristo con la Samaritana, la piedra sobre la que se amortajó el cuerpo de Cristo tras la muerte, el trono de Salomón, el cayado de Moisés, los restos de los inocentes mandados matar por Herodes, una porción de estiércol del asno a lomos del que Jesús entró en Jerusalén, el icono de la virgen Odigitria (que habría sido pintada por el evangelista San Lucas), los iconos considerados milagrosos, en tanto no fueron pintados por mano humana (ageropite), el Mandylion, el paño con la imagen impresa de Cristo (inicialmente en Edesa, donde tenía fama de hacer invencible la ciudad cuando se exponía en sus muros).

La reliquia más famosa que recorre la historia es ciertamente el santo Grial, es decir el cáliz en la que se habría recogido la sangre de Cristo durante la crucifixión, o bien la copa usada en la última Cena, pero no aconsejaría a Omar acometer su búsqueda (o queste), porque los sucesos precedentes no aconsejan semejante empresa.

\section{RESUMEN}

Reflexión llena de humor sobre la profusión y curiosa riqueza de los tesoros almacenados en los palacios y catedrales de la antigüedad.

Palabrasa clave: tesoros de iglesia, semiótica, catedrales, reliquias, fe, verdad.

\section{Waiting for a Semiotics of Treasures}

\section{ABSTRACT}

Reflection with a big sense of humour about the richness and curious variety of the treasures stored in the old cathedrals and palaces.

Keywords: chuch treasures, semiotics, cathedrals, relics, faith, truth.

\section{RÉSUMÉ}

Reflexion avec humeur sur la richesse et la profusion curieuse des trésors gardés aux palais et cathédrales de l' antiquité.

Mots-clé: trésors des églises, sémiotique, cathédral, relique, foi, vérité. 